See discussions, stats, and author profiles for this publication at: https://www.researchgate.net/publication/331140477

\title{
Functional over-redundancy and vulnerability of lichen communities decouple across spatial scales and environmental severity
}

Article in Science of The Total Environment · February 2019

DOI: 10.1016/j.scitotenv.2019.02.187

CITATIONS

READS

0

242

5 authors, including:

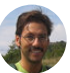

Paolo Giordani

Università degli Studi di Genova

134 PUBLICATIONS 1,658 CITATIONS

SEE PROFILE

Università degli Studi di Genova

26 PUBLICATIONS 160 CITATIONS

SEE PROFILE

Renato Benesperi

University of Florence

90 PUBLICATIONS 482 CITATIONS

SEE PROFILE

Guido Incerti
University of Udine
103 PUBLICATIONS 1,307 CITATIONS
SEE PROFILE

Some of the authors of this publication are also working on these related projects:

Dry grasslands and heaths of the Western Po Plain (Northern Italy) View project

Project RESTO CON LIFE "Island conservation in Tuscany, restoring habitats not only for birds" View project 


\title{
Accepted Manuscript
}

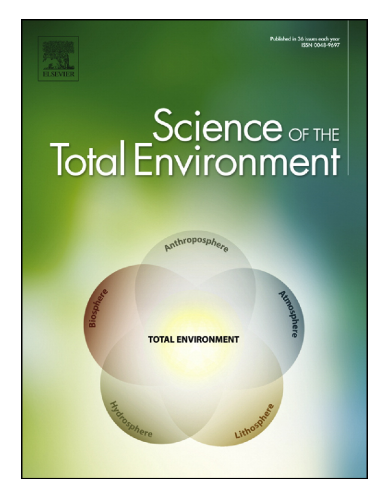

Paolo Giordani, Paola Malaspina, Renato Benesperi, Guido Incerti, Juri Nascimbene

\author{
PII: $\quad$ S0048-9697(19)30675-8 \\ DOI: $\quad$ https://doi.org/10.1016/j.scitotenv.2019.02.187 \\ Reference: $\quad$ STOTEN 30933 \\ To appear in: $\quad$ Science of the Total Environment \\ Received date: $\quad 7$ December 2018 \\ Revised date: $\quad 5$ February 2019 \\ Accepted date: $\quad 12$ February 2019
}

Please cite this article as: P. Giordani, P. Malaspina, R. Benesperi, et al., Functional over-redundancy and vulnerability of lichen communities decouple across spatial scales and environmental severity, Science of the Total Environment, https://doi.org/10.1016/ j.scitotenv.2019.02.187

This is a PDF file of an unedited manuscript that has been accepted for publication. As a service to our customers we are providing this early version of the manuscript. The manuscript will undergo copyediting, typesetting, and review of the resulting proof before it is published in its final form. Please note that during the production process errors may be discovered which could affect the content, and all legal disclaimers that apply to the journal pertain. 


\section{Functional over-redundancy and vulnerability of lichen communities decouple across spatial scales and environmental severity}

Paolo Giordani ${ }^{1}$, Paola Malaspina ${ }^{1}$, Renato Benesperi ${ }^{2}$, Guido Incerti ${ }^{3 *}$, Juri Nascimbene ${ }^{4}$

${ }^{1}$ Department of Pharmacy, University of Genova, Genova, Italy

${ }^{2}$ Department of Biology, University of Florence, Florence, Italy

${ }^{3}$ DI4A, Department of Agri-Food, Environmental and Animal Sciences, University of Udine, Udine, Italy

${ }^{4}$ Department of Biological, Geological and Environmental Sciences, University of Bologna, Bologna, Italy

* Corresponding author:

guido.incerti@uniud.it; tel.+390432558682

Dr. Guido Incerti

DI4A, Department of Agri-Food, Environmental and Animal Sciences

University ofUdine, Italy

via delle Scienze 206, Udine33100 (UD)

Phone: +390432558682

E-mail: guido.incerti@uniud.it

Keywords: Functional traits; rivet redundancy hypothesis; insurance hypothesis; transmitted solar radiation; epiphytes; rock-dwelling communities

Paper type: Research Paper 


\begin{abstract}
According to the insurance hypothesis, high taxonomic diversity should ensure ecosystem stability because of functional redundancy, whereas reduced functional diversity that results from species loss should affect ecosystem sensitivity, resilience, and vulnerability. However, even in species-rich ecosystems, functional over-redundancy (FOR; i.e., the tendency of most species to cluster into a few over-represented functional entities) in some cases may result in under-representation of many functions, and the ecosystem might become highly vulnerable. Using a stratified random sampling design with nested spatial levels (nine land use strata, 70 plots, 435 trees/rock outcrops, and 9845 quadrats), we recorded the occurrence of over 350 species of epiphytic and rock-dwelling lichens in semi-arid ecosystems in western Sardinia, where solar radiation defines a wide environmental gradient. By accounting for species functional traits, such as growth form, photosynthetic strategies, and reproductive strategies, we obtained 43 functional entities ( $>60 \%$ of all possible combinations) and tested the scale-dependency of FOR and functional vulnerability (FV, i.e., the risk of losing functional entities) by generalized linear mixed models. We found that FOR increased and FV decreased with increasing spatial scale, which supports the hypothesis of a cross-scale functional reinforcement. Decoupling of FOR and FV was far more evident for rock-dwelling compared with epiphytic communities, which reflects differing environmental conditions associated with substrate type. Our results indicate that increased warming and climatic extremes could exacerbate species clustering into the most resistant functional entities and thus enhance FOR at the community level. Therefore, high taxonomic diversity may not ensure systematic buffering of climate change impacts.
\end{abstract}




\section{Introduction}

Due to numerous disturbing factors, we are losing diversity at a rate never previously observed in the past. There is now a general agreement on the fact that diversity includes not only species richness, but also other aspects including, among others, the functional diversity, i.e. the value and range of species traits (Díaz and Cabido, 2001). These traits influence coexistence and ecosystem function. Their variation within communities can be quantified in terms of 'functional diversity' (Cadotte et al., 2011). Consequently, loss of ecological functions may affect ecosystem processes and services; resilience, and vulnerability to future changes (Foley et al., 2005; Hooper et al., 2005, Oliver et al., 2015). This may result in reduced management options (Carpenter et al., 2009). Therefore, future conservation strategies should incorporate species functional traits to assess and counteract ecosystem vulnerability to global change (Díaz and Cabido, 1997; Wright et al., 2004). According to the insurance hypothesis (Loreau et al., 2003; Yachi and Loreau, 1999), high species richness should ensure ecosystem stability because of functional redundancy; each function should be covered by several species, and result in a non-linear relationship between species and function losses (Ehrlich and Walker 1998). However, recent research warned against generalizing these assumptions. Even in species-rich ecosystems, ecosystem functioning could be vulnerable because of over-redundancy (i.e., the tendency of most species to cluster into a few overrepresented functional entities), as many functions may be under-represented; therefore, ecosystems may be highly vulnerable (Mouillot et al., 2014). Such findings were first described for fish faunas on tropical reefs, but should be further tested in other ecosystems and across different spatial scales and taxonomic groups to determine if there is a general pattern that might occur across ecosystems and inform environmental management strategies under global climate change.

Lichens, which are usually neglected symbiotic systems based on the interaction between fungi (mycobionts) and photosynthetic partners (photobionts) (Spribille et al., 2016), are particularly suited to testing the insurance hypothesis for two main reasons. First, lichen 
communities support multiple functions and services in terrestrial ecosystems (de Bello et al., 2010), such as by contributing to nutrient cycling (Cornelissen et al., 2007; Elbert et al., 2012), water flux regulation (Delgado-Baquerizo et al., 2016), soil formation (Zedda and Rambold, 2015), and providing food and nesting material to several vertebrate and invertebrate species (Asplund and Wardle, 2017). Second, lichen functional diversity is mainly mediated by photobiont type, thallus growth form, and dispersal strategy (Giordani, et al., 2012; Giordani et al., 2016); these attributes have been extensively reviewed and systematically classified for thousands of species (e.g., Nimis and Martellos, 2017). Such traits fit the definition of functional traits (Nock et al., 2016) because they directly affect growth, reproduction, and survival (Violle et al., 2007). For example, lichens with cyanobacterial photobionts contribute to biogeochemical nutrient cycling because they can fix atmospheric nitrogen (Rikkinen, 2015). Alternatively, crustose lichens showed higher desiccation tolerance and resistance to drought events compared with other growth forms (Phinney et al., 2018); these traits are related to lower thallus surface-to-volume ratio, which controls water uptake directly from atmospheric water vapor. Finally, contrasting reproductive strategies with different dispersal success can substantially affect lichen population dynamics and, therefore, their distributional patterns (Johansson et al., 2012; Scheidegger and Werth, 2009). Unfortunately, because of their poikilohydric nature that directly couples organism eco-physiology with environmental conditions, lichens are extremely vulnerable to human impacts, including air pollution (Giordani, 2007), land use change (Giordani et al., 2010), and climate change (Bargagli et al., 2002; Giordani and Incerti, 2008; Nascimbene et al., 2016). Therefore, testing the consistency of the insurance hypothesis in lichen communities may help elucidate their Functional Vulnerability (FV, i.e., the risk of functional entities loss) under the pressure of anthropogenic impacts that are driving global changes.

From a more theoretical perspective, integrating conventional community ecology approaches with information on species functional traits is crucial for understanding how ecosystem functions are filled by biological communities (Cadotte et al., 2011) and maintained along 
environmental and taxonomic richness gradients. Consistent with taxonomic diversity, patterns of functional (over-) redundancy and vulnerability are expected to be scale-dependent (Peterson et al., 1998). Spatial scale is intrinsically connected to ecosystem functioning because species interact with scale-dependent sets of ecological drivers and processes (Bastos et al., 2016; Lang et al., 2009). Consequently, it can be argued that potential erosion of functional diversity at the macroecological scale may not directly translate into a potential decline of ecosystem functioning (Mouillot et al., 2014). Indeed, cross-scale buffering effects can occur, such as when a functional group that consists of species that operate at different scales provides cross-scale functional reinforcement that fosters resilience of the ecosystem's functioning. Alternatively, cross-scale resilience complements within-scale resilience produced by overlap of ecological functions among species of different functional groups that operate at the same scales (Peterson et al., 1998).

Besides spatial scale, functional groups may cluster and interact differently along environmental gradients (Hobbs et al., 2006; Spasojevic and Suding, 2012; Bonanomi et al.,2016), which were predicted for plant interactions by the stress gradient hypothesis (e.g., Bertness and Callaway, 1994; Lortie and Callaway, 2006). In lichens, this phenomenon can even be observed along a gradient of micro-morphological substrate features, which control water and light availability and thus affect dispersal, growth rates, and photosynthetic processes (ConcostrinaZubiri et al., 2014; Giordani et al., 2014; Matos et al., 2015). At larger spatial scales, water availability and solar radiation may widely vary for epiphytic compared with rock-dwelling lichens; the former are exposed to less extreme conditions, especially in semi-arid environments (Giordani et al., 2014). Under such conditions, tree canopies protect epiphytes from intense solar radiation and increasing temperatures, and mitigates thallus water loss by prolonging water availability because it affects both leaf transpiration and water retention capacity of the bark (Gauslaa et al., 2007).

In this study, we explored functional over-redundancy (FOR) and vulnerability (FV) patterns of epiphytic and rock-dwelling lichen communities using a multi-scale approach, which 
included a species richness gradient that corresponded to land use intensity. We also explored the functional response to transmitted solar radiation at tree and rock outcrop scales, thus encompassing a wide environmental gradient. We used a stratified random sampling design with nested spatial levels to test the scale-dependency of the observed patterns. In particular, we hypothesized that (1) FOR increases and FV decreases with increasing spatial scale, because species will cluster into a few over-represented functions and there will be cross-scale functional reinforcement, and (2) decoupling of FOR and FV differs between rock-dwelling and epiphytic communities because of different environmental conditions associated with substrate type. In particular, we expect that decoupling of FOR and FV would be far more evident for rock-dwelling compared with epiphytic communities, reflecting more severe conditions for the former. Our study aimed to provide information about potential threats posed by global change to lichen community functioning.

\section{Materials and methods}

\subsection{Survey area}

The study was carried out in a $1260-\mathrm{km}^{2}$ area of western Sardinia, Italy, where human population density is very low ( 40 persons $\left./ \mathrm{km}^{2}\right)$ and local sources of air pollution are absent. Along an altitudinal gradient that ranged from sea level to $1200 \mathrm{~m}$, the main vegetation types were Mediterranean maquis, Mediterranean garigue, and evergreen holm oak forest; the latter was mixed with deciduous oaks, which demonstrated a progressive compositional shift from xero-thermophilic to mesophilic communities up to the highest altitude. Along the same altitudinal gradient, natural plant communities were locally replaced or mixed with stone pine plantations, cork oak stands, arable fields, and pastures for sheep breeding. Mean annual rainfall and temperature range from $600 \mathrm{~mm}$ and $15^{\circ} \mathrm{C}$, respectively, along the coast to $110 \mathrm{~mm}$ and $13^{\circ} \mathrm{C}$, respectively, at the highest elevations. The main rock substrates include basalts of alkaline, transitional, and sub-alkaline affinity from the 
Plio-Pleistocene cycle, and rhyolite and andesite rocks of the Oligo-Miocene calc-alkaline cycle (Carmignani et al., 2016).

\subsection{Sampling design and data collection}

Based on a stratified random sampling design, we randomly selected coordinates pairs (UTM, WGS84) to obtain 70 sampling points, which were allocated into nine strata obtained by aggregation of CORINE land cover classes, proportionally to the surface occupied by each stratum within the survey area (Table 1). In the field, each sampling point was positioned using a GPS and used as the SW corner of a N-oriented $20 \times 20-\mathrm{m}$ plot. Within each plot, we randomly selected and sampled 1 to 6 trees and 1 to 6 rock outcrops; the numbers of trees and rock outcrops sampled were proportional to the area covered by each substrate type. The occurrence of corticolous lichen species was recorded in each $10 \times 10-\mathrm{cm}$ quadrat of a sampling grid, which consisted of a $10 \times 50-\mathrm{cm}$ ladder that was divided into five quadrats and systematically placed on the N, E, S, and W sides of each tree bole, with the top edge $1.5 \mathrm{~m}$ above ground level; these methods follow those described by Asta et al. (2002). Twenty quadrats were sampled for each tree. Similarly, we sampled epilithic (rock-dwelling) species occurrence in each of $2510 \times 10-\mathrm{cm}$ quadrats using a $50 \times 50-\mathrm{cm}$ grid that was systematically centered on each rock outcrop. Overall, in 70 plots (64 of which had trees and 66 had rock outcrops), we sampled 4120 quadrats on 206 trees and 5725 quadrats on 229 rock outcrops (Table 1). Most species of lichenized and lichenicolous fungi were identified in the field. Critical specimens were collected and identified in the laboratory using standard stereo- and light microscopy techniques.

As previously described (Giordani et al., 2014), we used Gap Light Analyzer (Frazer et al.,1999) to calculate direct and diffuse transmitted solar radiation based on hemispherical photographs taken at each subplot (i.e., either tree or rock outcrop). Hemispherical photographs can provide accurate estimates of Leaf Area Index, i.e. the ratio of leaf area and sky area (Bramer et al. 
2018). Photographs were taken from the end of June to mid-July, which is at the end of leaf flushing and shedding periods of the dominant tree species (Quercus spp.) when canopy cover is stable (Ogaya and Penuelas, 2004). The hemispherical photograph approach facilitates estimation of solar radiation over long periods in different sampling units and also accounts for local variation of site morphology (e.g., slope and aspect) along with canopy coverage. As solar radiation can widely affect lichen performance, especially in semi-arid environments where it is directly related to temperature and water availability (Giordani et al., 2014), we considered it a proxy of environmental severity at the sampling sites. Actually, solar radiation is among the main factors determining microclimatic factors, such as local temperature, humidity and evapotranspiration (Bramer et al., 2018; Zellweger et al., 2019).

\subsection{Functional entities and indices}

Following Nimis and Martellos (2017), we considered three functional traits for each lichen species: Growth Form (GF), Photosynthetic Strategy (PS), and Reproductive Strategy (RS) (Table 2). Attributes for GF, PS, and RS produced a theoretical total of 240 Functional Entities (FEs), i.e. unique combinations of trait values.

As described by Mouillot et al. (2014), we calculated two indices of functionality for lichen communities recorded in each sampling unit at every spatial level (i.e., land use stratum, plot, tree/rock outcrop, and quadrat). For each community and sampling unit, FOR represented the level of over-representation of FEs in terms of species richness and was calculated as:

$$
F O R=\frac{1}{S} \sum_{i=1}^{N}\left[\max \left(s_{i}, F R\right)-F R\right]
$$

where $N$ is the total number of FEs in the given community and sampling unit, $s_{i}$ is the number of species in the $i$-th $\mathrm{FE}$, and $F R$ is the functional redundancy. $F R$ is the ratio between species richness $(S)$ and the number of FEs, and is calculated as: 


$$
F R=\frac{1}{N} \sum_{i=1}^{N} s_{i}=\frac{S}{N}
$$

FV describes the risk of FE loss and is calculated as follows:

$$
F V=1-\frac{1}{N} \sum_{i=1}^{N} \min \left(s_{i}-1,1\right)
$$

Consequently, FR ranges between 1 (all FEs are non-redundant) and $S$ (when a single FE includes all the species in the community); in both cases, $F O R=0$ indicates absence of over-redundancy, whereas FOR $>0$ indicates over-redundancy (i.e., uneven species distribution among different FEs). Alternatively, $F V$ ranges between 0 (all FEs are redundant; i.e., represented by more than one species) and 1 (all FEs are non-redundant).

\subsection{Data analysis}

Variations in FOR and FV along species richness gradients were separately tested for rock-dwelling and epiphytic lichens at each spatial scale (i.e., quadrats, rock/tree subplots, plots, and land use strata) using univariate logarithmic regression models. Generalized linear mixed models were fitted to total (i.e., direct and diffused) solar radiation, including first-order and interactive fixed effects of substrate type, land use (nine levels, Table 1), nested random effects of sampling plot, and their interactions. Substrate type effects on FOR and FV were tested using generalized linear mixed models with transmitted solar radiation components and their interactions as continuous covariates. Pairwise differences were assessed for all cases using HSD post-hoc tests for unequal sample sizes at $\alpha=0.05$.

\section{Results}

\subsection{Functional composition of epiphytic and rock-dwelling communities}

Overall, we found 43 FEs (Supplementary Table S1), which represented $18 \%$ of all the theoretical combinations produced by factorially combining GF, PS, and RS attributes. Nineteen FEs occurred 
on both rocks and trees; these included nearly all GF, PS, and RS attributes, with the exceptions of the fruticose-filamentous and foliose-umbilicate GFs. Crustose and foliose broad-lobed lichens, with chlorococcoid algae and sexual reproduction, predominated on both substrate types across all land use strata (Supplementary Table S1). Alternatively, foliose narrow-lobed lichens with chlorococcoid algae were more frequent on trees than rocks, whereas non-lichenized and lichenicolous fungi showed an opposite pattern and were more frequent on rocks (Supplementary Table S1). Twelve FEs were exclusively recorded on rocks, including four FEs of folioseumbilicate lichens with both cyanobacteria and chlorococcoid algae, and four FEs of fruticose lichens with cyanobacteria and Trentepohlia as photobionts (Supplementary Table S1). Similarly, 12 FEs were exclusively epiphytic; seven were macrolichens (fruticose or foliose GFs) and most had filamentous cyanobacteria as photobionts (Supplementary Table S1). Most exclusively epiphytic FEs were extremely rare and occurred in fewer than 50 quadrats (out of 4120) throughout the entire survey area.

\subsection{FOR and FV across spatial scales and species richness gradients}

FOR increased with spatial scale on both substrate types, although rock-dwelling lichen values were consistently higher than epiphyte values (Fig. 1). This pattern was congruent with that observed for FR median values, which ranged for rock-dwelling and epiphytic communities from 2.4 and 1.8 species per FE, respectively, at the quadrat level, to 6.3 and 4.5 species per FE, respectively, at the land use scale. Alternatively, FV showed contrasting spatial patterns between the two substrates. For epiphytes, FV progressively decreased with spatial scale, with median values that ranged from 0.72 at the quadrat level to 0.35 at the land use scale (Fig. 1). However, FV of rock-dwelling communities was much less variable, with median values that were not significantly different across spatial scales and ranged between 0.43 at the land use scale and 0.55 at the subplot scale (Fig. 1). Consequently, FV differences between rock-dwelling and epiphytic communities varied in 
magnitude and trend across spatial scales; epilithic lichens had greater FV than epiphytes at smaller spatial levels but not at the land use scale (Fig. 1).

At each spatial level, FOR consistently increased with species richness (Fig.2), and FOR of rock-dwelling communities was consistently higher compared with that of epiphytes across the entire species richness gradient. The only exceptions to this pattern were the non-over-redundant (i.e., FOR $=0$ ) assemblages, which were progressively rarer at increasing spatial scales. Interestingly, at quadrat and subplot levels, these assemblages were rarely $(\mathrm{N}=484$ out of 10388$)$ non-redundant and monospecific (and therefore highly vulnerable), and most often $(\mathrm{N}=3648$ ) consisted of one FE composed of several species (with maxima at the quadrat level of 11 and 12 for rock-dwelling and epiphytes, respectively). Along the same species richness gradient, FV was not as straightforward. In the case of epiphytes, FV showed a negative association with richness, which was mostly consistent across spatial scales, except at the land use level (Fig. 2). This trend was much less evident for rock-dwelling communities, which showed FV association with species richness at the quadrat level but no significant relationships at larger scales (Fig. 2).

\subsection{Functional response to solar radiation}

Epiphytes experienced significantly milder solar radiation conditions compared with rock-dwelling communities (Fig. 3). This solar radiation difference was less clear in closed forest conditions, such as in stone pine and broadleaved stands, but far more evident in woodland clearances and especially over rock outcrops in open land, where total transmitted solar radiation had $5 \times$ higher peaks compared with isolated tree bark (Fig. 3). Expectedly, environmental severity, as inferred by transmitted solar radiation, was also highly variable at the local scale, as indicated by the significant random effect of the plot, which was nested within land use class (Table 3). However, because the maxima exceeded 6.4 $\mathrm{MJ} \mathrm{m}^{-2} \mathrm{~d}^{-1}$ (Fig. 3), the sampling sites had a wide gradient of environmental conditions and encompassed very harsh conditions for rock-dwelling communities and mostly mild conditions for epiphytes. 
Lichen functional response showed interesting patterns along the environmental severity gradient. In particular, we found a significant effect of the transmitted solar radiation on FOR, which was consistent for both the direct and diffused radiation (Table 4). Excluding the large amount of noise, such an effect was significant, even when tested with simple univariate models (Fig. 4); this indicates an enhancing role of solar radiation on FOR that is potentially linked to competitive exclusion and high specialization in extreme niches under very high irradiance. However, light effects on FOR were not consistent between rock-dwelling and epiphytic communities, as shown by the significant effects of substrate type and its interactions with transmitted light components (Table 4). Indeed, FOR exacerbation at high radiation densities was limited to epilithic communities that were exposed to harsh conditions; alternatively, epiphytes did not significantly respond compared with rock-dwelling communities, likely because of the limited radiation gradient below the tree canopy (Supplementary Fig. S1). In contrast, FV was negatively associated with transmitted direct and diffused solar radiation (Fig. 4). Although FV showed limited decrease along the light resource gradient and higher variability among observations compared with FOR (Fig. 4), the effect depended on substrate (Table 4).

\section{Discussion}

We explored FOR and FV patterns of lichen communities in a Mediterranean area at different spatial scales relative to species richness and substrate type, and used transmitted solar radiation to infer an environmental severity gradient. In particular, we tested the non-mutually exclusive hypotheses that FOR increases and FV decreases with increasing spatial scale (hypothesis 1), and rock-dwelling and epiphytic communities show contrasting patterns of FOR and FV relative to different environmental severity experienced over different substrate types (hypothesis 2). Our results revealed scale- and substrate-dependent patterns for these functional descriptors, which partially confirmed our two hypotheses. In accordance with hypothesis 1, we demonstrated that 
FOR in lichen communities is scale-dependent. FOR patterns were consistent between rockdwelling and epiphytic lichens; FOR increased with species number and was substantially saturated at intermediate values of species richness. This pattern corresponded to a progressive increase of FOR with increasing spatial scale, which likely reflected the process of species accumulation underlying the well-known species-area relationship (MacArthur and Wilson, 1967).

Our FOR findings also supported hypothesis 2: FOR magnitude of rock-dwelling lichens was much higher than that of epiphytic communities across all tested conditions, which supports a substrate-dependent response related to environmental severity. Notably, in the study area, solar radiation on rock outcrops was, on average, twofold higher than that under tree canopies, which was quantitatively consistent with the maximum FOR difference between the corresponding lichen communities. Besides the obvious effects on photosynthesis, solar radiation was considered a reliable proxy for environmental severity at the sampling sites, as it is strictly related to water availability and temperature (Díaz-Barradas et al., 2018), which are fundamental for lichen physiology, especially in semi-arid ecosystems (Giordani et al., 2014; Matos et al., 2015; Tretiach et al., 2012). Consequently, our results indicate that, in lichen communities, species tend to cluster into a few over-represented FEs increases as environmental conditions become harsher and that, under these conditions, diversity-stability relationships (the insurance hypothesis; Yachi and Loreau, 1999) do not apply.

These findings do not contradict previous evidence and theory on the stabilizing effect of diversity on ecosystem functioning, which were mostly based on observations in systems exposed to mildly fluctuating environmental conditions (Cardinale et al., 2012; De Boeck et al., 2018). Further supporting evidence was reported from a recent meta-analysis on biodiversity-stability relationships under climate extremes (De Boeck et al., 2018); under climate extremes, ecosystem functioning was not differently protected by either high or low plant diversity. In the case of lichens, epiphytic compared with rock-dwelling communities are supposed to experience milder 
conditions because of the ameliorating effect of tree canopies by filtering solar radiation and mitigating desiccation (Bramer et al., 2018; Gauslaa et al., 2007). Forest canopies buffer temperature extremes, thus mitigating the thermodynamic constraints on species growth, reproduction, and survival (Zellweger et al., 2019). As far as water availability is concerned, the effects of vegetation are complex: basically, higher vegetation cover allows greater evapotranspiration, due to the effects of leaf area; but on the contrary, a high level of canopy shading can also reduce evapotranspiration (Bramer et al., 2018). At substrate level, compared with rock substrates, tree bark could also prolong water availability because of the high water retention capacity and buffering against extreme temperatures (Středa et al., 2015). Indeed, in semi-arid environments, sun-exposed rock outcrops provide extremely severe conditions that can be critical for lichen growth, especially in the summer, with a persistent water deficit due to climatic drought conditions and rapid desiccation related to high temperatures (Giordani et al., 2014; Sterflinger and Krumbein, 1995; Incerti et al., 2011). The higher FOR of rock-dwelling communities may reflect adaptive convergence in response to extreme environmental severity (Bruno et al., 2016), which led to selection of the most resistant FEs.

In contrast to our FOR observations, hypothesis 2 was not supported by FV, as FV patterns were poorly or not related to substrate type and spatial scale. Therefore, our findings indicate that FOR does not evenly reflect FV across spatial scales and substrates. We observed that epiphytic lichen community vulnerability presumably depended on interactions between processes acting at the stand scale, including trophic interactions or acclimation, and at the landscape scale, including gene flow and dispersal limitation, even though the general relevance of these events for lichen ecology is not yet sufficiently understood (Ellis, 2013). Our trait-focused approach contributed to generalization of these processes and revealed that, at least for epiphytic lichens, the scaledependency of FV is limited to the small (i.e., micro-sites, trees) and intermediate (i.e., plots) spatial 
levels; increasing species richness reduced the risk of functional loss, which is consistent with the insurance hypothesis (Yachi and Loreau, 1999).

Accordingly, as predicted by the rivet redundancy hypothesis (Ehrlich and Walker, 1998), the breadth of functions associated with lichen assemblages at a within-plot scale would be less vulnerable in species-rich communities, where limited species loss may not be detrimental to community functioning. Alternatively, at larger spatial scales (such as homogeneous land use parcels), FV of epiphytic lichens is independent of species richness, even with highly vulnerable communities that are not affected by an increase in species number. For example, at the landscape scale, the most taxonomically diverse assemblages and those threefold less diverse would have equal FV. Such a shift in the functional response of epiphytic lichens across spatial scales, with a clear decoupling of FV and taxonomic diversity across different spatial scales, indicates that the level of FV for these communities likely depends on processes that act on small spatial scales. These findings could have relevant implications for conservation strategies because generic habitat protection directives (e.g., as assigned in Europe by the Habitat Directive; Council Directive 92/43/EEC) may not be effective for preserving the functional diversity of epiphytic lichen communities. Instead, there should be specific measures at the very small scale (e.g., site and tree; Benesperi et al., 2018), where preserving species richness would prevent the loss of FEs.

In the case of rock-dwelling communities, FV was not buffered by increasing species richness and, consistently, did not substantially change across spatial scales. This pattern is consistent with that found by Mouillot et al. (2014) for tropical fish faunas, which indicates that species richness may fail to protect communities and ecosystems against function loss. Even in species-rich sites, FV is not necessarily increased because, as a result of the occurrence and magnitude of FOR, some FEs are under-represented (e.g., by a single species). From this perspective, a generic conservation strategy that focuses on the increasing of species richness may fail to preserve the functional diversity of lichen assemblages and therefore the complete ecosystem 
functioning. To overcome this issue, specific protection should be assigned to the most vulnerable FEs.

Given the relatively low variability of macroclimatic factors in the study area, in our models we focused on the effects of microclimatic and local variables (e.g. substrate). Although the macroclimate is critical to making wider-ranging considerations on the effects of global change, our data can contribute to describing indirect effects on a local scale, the relevance of which has recently been increasingly highlighted. In fact, recent progresses in microclimate ecology are emphasizing the view that microclimate variability may modulate the impacts of climate change, thus stressing the importance of considering the effect of microclimatic conditions for improving the reliability of our predictions on the response of organisms to global changes (Bramer et al., 2018; Zellweger et al., 2019). In this perspective, the contrasting functional spatial patterns related to substrate types (i.e. epiphytes vs rock-dwelling species) and local solar radiation corroborate the idea that global change could exacerbate species clustering into the few most resistant FEs, and thus enhances FV at the community level. This would imply that, in accordance with a recent synthesis on plant communities structure (De Boek et al., 2018), high taxonomic diversity may not ensure systematic buffering of global change impacts. Indeed, besides impacting species richness (Newbold et al., 2015), global change is expected to trigger FV; this hypothesis was corroborated by recent studies that documented the loss of entire functional groups along climatic gradients (Giordani et al., 2014; Nascimbene and Marini, 2015). On the other hand, the availability of suitable micro-habitats within a given macro-habitat may reduce the FV of lichen communities to global change (Ellis, 2013). For example, in shrubby semi-arid rangelands, high geodiversity at small spatial scales (centimeters to few decimeters) enhances the on-site retention of water and soil resources, and limits the vulnerability of these ecosystems to prolonged droughts and climatic changes (Stavi et al., 2018). In the case of lichens, the relevance of small-scale events to FV should be even more evident, as was previously shown for different small sessile short-range organisms 
(Schooler et al., 2017). Indeed, although small-scale impacts are generally subsumed within ecological niches at a coarse scale (Pearson and Dawson, 2003), the ecological niche of lichens is mainly determined by their physiological performance at a microclimatic scale (Schroeter et al., 2010). In this perspective, our study highlights the need for specific, local management practices to counteract global change effects on lichen communities.

\section{Acknowledgements}

This work was supported by the Italian Ministero dell'Istruzione,dell’Università e della Ricerca, project F.I.S.R.-M.I.C.E.N.A. 2006.GI was supported by a PRID 2017 fund by DI4A, University of Udine. We thank Mallory Eckstut, PhD, from Edanz Group (www.edanzediting.com/ac) for editing a draft of this manuscript.

\section{References}

Asplund, J., \& Wardle, D. A. (2017). How lichens impact on terrestrial community and ecosystem properties. Biological Reviews of the Cambridge Philosophical Society,92, 1720-1738.

Asta, J., Erhardt, W., Ferretti, M., Fornasier, F., Kirschbaum, U., Nimis, ... Wirth, V. (2002). Mapping Lichen Diversity as an Indicator of Environmental Quality. In P. L. Nimis, C. Scheidegger, \& P. A. Wolseley (Eds.), Monitoring with Lichens - Monitoring Lichens (pp. 273-279). Dordrecht, The Netherlands: Springer.

Bargagli, R., \& Mikhailova, I. (2002). Accumulation of Inorganic Contaminants. In P. L. Nimis, C. Scheidegger, \& P. A. Wolseley (Eds.), Monitoring with Lichens - Monitoring Lichens (pp. 65-84). Springer Netherlands.

Bastos, R., D’Amen, M., Vicente, J., Santos, M., Yu, H., Eitelberg, D., ... Cabral, J. A. (2016). A multi-scale looping approach to predict spatially dynamic patterns of functional species richness in changing landscapes. Ecological Indicators, 64, 92-104.

Benesperi, R., Nascimbene, J., Lazzaro, L., Bianchi, E., Tepsich, A., Longinotti, S., \& Giordani, P. (2018). Successful conservation of the endangered forest lichen Lobaria pulmonaria requires knowledge of fine-scale population structure. Fungal Ecology, 33, 65-71.

Bertness, M.D., \& Callaway, R. (1994). Positive interactions in communities. Trends in Ecology and Evolution, 9, 191193.

Bonanomi, G., Stinca, A., Chirico, G.B., Ciaschetti, G., Saracino, A., Incerti, G. (2016). Cushion plant morphology controls biogenic capability and facilitation effects of Silene acaulis along an elevation gradient. Functional Ecology, 30, 1216-1226. 
Bramer, I., Anderson, B.J., Bennie, J., Bladon, A.J., De Frenne, P., Hemmingk, D., Hill, R.A., Kearney, M.R., \& istian Körner, C., Korstjens, A.H., Lenoir, J., Maclean, I.M.D., Marsh, C.D., Morecroft, M.D., Ohlemüller, R., Slater, H.D., Suggittkk, A.J., Zellweger, F., \& Gillingham, P.K. (2018). Advances in Monitoring and Modelling Climate at Ecologically Relevant Scales. In D.A. Bohan, A.J. Dumbrell, G. Woodward, M. Jackson (Eds.) Next Generation Biomonitoring: Part 1 (pp. 101-161), series Advances in Ecological Research, 58, Amsterdam: Elsevier. Bruno, D., Gutiérrez-Cánovas, C., Sánchez-Fernández, D., Velasco, J., \& Nilsson, C. (2016). Impacts of environmental filters on functional redundancy in riparian vegetation. Journal of Applied Ecology. 53. 846-855.

Cadotte, M. W., Carscadden, K., \& Mirotchnick, N. (2011). Beyond species: Functional diversity and the maintenance of ecological processes and services. Journal of Applied Ecology, 48, 1079-1087.

Cardinale, B. J., Duffy, J. E., Gonzalez, A., Hooper, D. U., Perrings, C., Venail, P., ... Naeem, S. (2012). Biodiversity loss and its impact on humanity. Nature, 486, 59-67.

Carmignani, L., Oggiano, G., Funedda, A., Conti, P., \& Pasci, S. (2016). The geological map of Sardinia (Italy) at 1:250,000 scale. Journal of Maps, 12, 826-835.

Carpenter S.R., Mooney H.A., Agard J., Capistrano D., DeFries R.S., Díaz S., ... Whyte A. (2009). Science for managing ecosystem services: Beyond the Millennium Ecosystem Assessment. Proceedings of the National Academy of Sciences, 106, 1305-1312.

Concostrina-Zubiri, L., Pescador, D. S., Martínez, I., \& Escudero, A. (2014). Climate and small scale factors determine functional diversity shifts of biological soil crusts in Iberian drylands. Biodiversity and Conservation,23,17571770 .

Cornelissen, J. H. C., Lang, S. I., Soudzilovskaia, N. A., \& During, H. J. (2007). Comparative cryptogam ecology: a review of bryophyte and lichen traits that drive biogeochemistry. Annals of Botany, 99, 987-1001.

de Bello, F., Lavorel, S., Díaz, S., Harrington, R., Cornelissen, J. H. C., Bardgett, R. D., ... Harrison, P. A. (2010). Towards an assessment of multiple ecosystem processes and services via functional traits. Biodiversity and Conservation, 19, 2873-2893.

De Boeck, H. J., Bloor, J. M. G., Kreyling, J., Ransijn, J. C. G., Nijs, I., Jentsch, A., \& Zeiter, M. (2018). Patterns and drivers of biodiversity-stability relationships under climate extremes. Journal of Ecology, 106, 890-902.

Delgado-Baquerizo, M., Maestre, F. T., Eldridge, D. J., Bowker, M. A., Ochoa, V., Gozalo, B., ... Singh, B. K. (2016). Biocrust-forming mosses mitigate the negative impacts of increasing aridity on ecosystem multifunctionality in drylands. New Phytologist, 209, 1540-1552.

Díaz, S., \& Cabido, M. (1997). Plant functional types and ecosystem function in relation to global change. Journal of Vegetation Science, 8, 463-474.

Díaz-Barradas, M. C., Zunzunegui, M., Alvarez-Cansino, L., Esquivias, M. P., Valera, J., \& Rodríguez, H. (2018). How do Mediterranean shrub species cope with shade? Ecophysiological response to different light intensities. Plant Biology, 20, 296-306.

Díaz, S. \& Cabido, M. (2001). Vive la difference: plant functional diversity matters to ecosystem processes. Trends in Ecology \& Evolution, 16, 646-655.

Ehrlich, P., \& Walker, B. (1998). Rivets and Redundancy. BioScience, 48, 387-387.

Elbert, W., Weber, B., Burrows, S., Steinkamp, J., Büdel, B., Andreae, M. O., \& Pöschl, U. (2012). Contribution of cryptogamic covers to the global cycles of carbon and nitrogen. Nature Geoscience, 5, 459-462.

Ellis, C. J. (2013). A risk-based model of climate change threat: hazard, exposure, and vulnerability in the ecology of lichen epiphytes. Botany, 91, 1-11. 
Foley, J. A., DeFries, R., Asner, G. P., Barford, C., Bonan, G., Carpenter, S. R., ... Snyder, P. K. (2005). Global Consequences of Land Use. Science, 309, 570-574.

Frazer, G. W., Cahnam, C. D., \& Lertzman, K. P. (1999). Gap Light Analyzer (Version 2.0): Imaging software to extract canopy structure and gap light transmission indices from true-colour fisheye photographs, users manual and program documentation. Burnaby, British Columbia, Canada: Simon Fraser University, and Millbrook, New York, USA: Institute of Ecosystem Studies. Retrieved from https://www.sfu.ca/rem/forestry/downloads/gap-lightanalyzer.html

Gauslaa, Y., Palmqvist, K., Solhaug, K. A., Holien, H., Hilmo, O., Nybakken, L., ... Ohlson, M. (2007). Growth of epiphytic old forest lichens across climatic and successional gradients. Canadian Journal of Forest Research, 37 , 1832-1845.

Giordani, P. (2007). Is the diversity of epiphytic lichens a reliable indicator of air pollution? A case study from Italy. Environmental Pollution, 146, 317-323.

Giordani, P., Brunialti, G., Bacaro, G., \& Nascimbene, J. (2012). Functional traits of epiphytic lichens as potential indicators of environmental conditions in forest ecosystems. Ecological Indicators, 18, 413-420.

Giordani, P., \& Incerti, G. (2008). The influence of climate on the distribution of lichens: a case study in a borderline area (Liguria, NW Italy). Plant Ecology, 195, 257-272.

Giordani, P., Incerti, G., Rizzi, G., Ginaldi, F., Viglione, S., Rellini, I., \& Modenesi, P. (2010). Land use intensity drives the local variation of lichen diversity in Mediterranean ecosystems sensitive to desertification. Bibliotheca Lichenologica, 105, 139-48.

Giordani, P., Incerti, G., Rizzi, G., Rellini, I., Nimis, P. L., \& Modenesi, P. (2014). Functional traits of cryptogams in Mediterranean ecosystems are driven by water, light and substrate interactions. Journal of Vegetation Science, 25, 778-792.

Giordani, P., Rizzi, G., Caselli, A., Modenesi, P., Malaspina, P., \& Mariotti, M.G. (2016). Fire affects the functional diversity of epilithic lichen communities. Fungal Ecology, 20, 49-55.

Hobbs, R. J., Arico, S. , Aronson, J., Baron, J. S., Bridgewater, P., Cramer, V. A., ... Zobel, M. (2006). Novel ecosystems: theoretical and management aspects of the new ecological world order. Global Ecology and Biogeography, 15, 1-7.

Hooper, D. U., Chapin, I., Ewel, J. J., Hector, A., Inchausti, P., Lavorel, S., ... Wardle, D. A. (2005). Effects of biodiversity on ecosystem functioning: A consensus of current knowledge. Ecological Monographs, 75, 3-35.

Incerti, G., Bonanomi, G., Giannino, F., Rutigliano, F.A., Piermatteo, D., Castaldi, S., ... Mazzoleni, S. (2011). Litter decomposition in Mediterranean ecosystems: Modelling the controlling role of climatic conditions and litter quality. Applied Soil Ecology, 49, 148-157.

Johansson, V., Ranius, T., \& Snäll, T. (2012). Epiphyte metapopulation dynamics are explained by species traits, connectivity, and patch dynamics. Ecology, 93, 235-241.

Lang, S. I., Cornelissen, J. H. C., Hölzer, A., Ter Braak, C. J. F., Ahrens, M., Callaghan, T. V., \& Aerts, R. (2009). Determinants of cryptogam composition and diversity in Sphagnum-dominated peatlands: the importance of temporal, spatial and functional scales. Journal of Ecology, 97, 299-310.

Loreau, M., Mouquet, N., \& Gonzalez, A. (2003). Biodiversity as spatial insurance in heterogeneous landscapes. Proceedings of the National Academy of Sciences of the United States of America, 100, 12765-12770.

Lortie, C.J., \& Callaway, R.M. (2006). Re-analysis of meta-analysis: support for the stress-gradient hypothesis. Journal of Ecology, 94, 7-16. 
MacArthur, R.H. \& Wilson, E.O. (1967). The Theory of Island Biogeography. Princeton, NJ, USA: Princeton University Press.

Matos, P., Pinho, P., Aragón, G., Martínez, I., Nunes, A., Soares, A. M. V. M., \& Branquinho, C. (2015). Lichen traits responding to aridity. Journal of Ecology, 103, 451-458.

Mouillot, D., Villeger, S., Parravicini, V., Kulbicki, M., Arias-Gonzalez, J. E., Bender, M., ... Bellwood, D. R. (2014). Functional over-redundancy and high functional vulnerability in global fish faunas on tropical reefs. Proceedings of the National Academy of Sciences, 111, 13757-13762.

Nascimbene, J., Casazza, G., Benesperi, R., Catalano, I., Cataldo, D., Grillo, M., ... Giordani, P. (2016). Climate change fosters the decline of epiphytic Lobaria species in Italy. Biological Conservation, 201, 377-384.

Nascimbene, J., \& Marini, L. (2015). Epiphytic lichen diversity along elevational gradients: biological traits reveal a complex response to water and energy. Journal of Biogeography, 42, 1222-1232.

Newbold, T., Hudson, L. N., Hill, S. L. L., Contu, S., Lysenko, I., Senior, R. A., ... Purvis, A. (2015). Global effects of land use on local terrestrial biodiversity. Nature, 520, 45-50.

Nimis, P. L., \& Martellos, S. (2017). ITALIC 5.0 - the information system on Italian lichens. Retrieved March 20, 2018, from http://dryades.units.it/italic

Nock, C. A., Vogt, R. J., \& Beisner, B. E. (2016) Functional Traits. In eLS. Chichester, UK: John Wiley \& Sons Ltd. Chichester. Retrieved from http://www.els.net [doi: 10.1002/9780470015902.a0026282]

Ogaya, R., \& Penuelas, J. (2004). Phenological patterns of Quercus ilex, Phillyrea latifolia, and Arbutus unedo growing under a field experimental drought. Ecoscience, 11, 263-270.

Oliver, T.H., Heard M.S., Isaac N.J.B., Roy D.B., Procter D., Eigenbrod F., ... Bullock J.M. (2015). Biodiversity and Resilience of Ecosystem Functions. Trends in Ecology \& Evolution, 30, 673-684.

Pearson, R. G., \& Dawson, T. P. (2003). Predicting the impacts of climate change on the distribution of species: are bioclimate envelope models useful? Global Ecology and Biogeography, 12, 361-371.

Peterson, G., Allen, C. R., \& Holling, C. S. (1998). Ecological resilience, biodiversity, and scale. Ecosystems, 1, 6-18.

Phinney, N. H., Solhaug, K. A., \& Gauslaa, Y. (2018). Rapid resurrection of chlorolichens in humid air: specific thallus mass drives rehydration and reactivation kinetics. Environmental and Experimental Botany, 148, 184-191.

Rikkinen, J. (2015). Cyanolichens. Biodiversity and Conservation, 24, 973-993.

Scheidegger, C., \& Werth, S. (2009). Conservation strategies for lichens: insights from population biology. Fungal Biology Reviews, 23, 55-66.

Schooler, N. K., Dugan, J. E., Hubbard, D. M., \& Straughan, D. (2017). Local scale processes drive long-term change in biodiversity of sandy beach ecosystems. Ecology and Evolution, 7, 4822-4834.

Schroeter, B., Green, T. A., Pannewitz, S., Schlensog, M., \& Sancho, L. G. (2010). Fourteen degrees of latitude and a continent apart: comparison of lichen activity over two years at continental and maritime Antarctic sites. Antarctic Science, 22, 681-690.

Spasojevic, M.J., \& Suding, K.N. (2012). Inferring community assembly mechanisms from functional diversity patterns: the importance of multiple assembly processes. Journal of Ecology, 100, 652-661.

Spribille, T., Tuovinen, V., Resl, P., Vanderpool, D., Wolinski, H., Aime, M. C., .. McCutcheon, J. P. (2016). Basidiomycete yeasts in the cortex of ascomycete macrolichens. Science, 353,488-492. 
Stavi, I., Rachmilevitch, S., \& Yizhaq, H. (2018). Small-scale Geodiversity Regulates Functioning, Connectivity, and Productivity of Shrubby, Semi-arid Rangelands. Land Degradation \& Development, 29, 205-209.

Sterflinger, K., \& Krumbein, W. E. (1995). Multiple Stress Factors affecting Growth of Rock-inhabiting Black Fungi. Botanica Acta, 108, 490-496.

Středa, T., Litschmann, T., \& Středová, H. (2015). Relationship between tree bark surface temperature and selected meteorological elements. Contributions to Geophysics and Geodesy, 45, 299-311.

Tretiach, M., Pavanetto, S., Pittao, E., Sanità di Toppi, L., \& Piccotto, M. (2012). Water availability modifies tolerance to photo-oxidative pollutants in transplants of the lichen Flavoparmelia caperata. Oecologia, 168, 589-599.

Violle, C., Navas, M.-L., Vile, D., Kazakou, E., Fortunel, C., Hummel, I., \& Garnier, E. (2007). Let the concept of trait be functional! Oikos, 116, 882-892.

Wright, I. J., Reich, P. B., Westoby, M., Ackerly, D. D., Baruch, Z., Bongers, F., ... Villar, R. (2004). The worldwide leaf economics spectrum. Nature, 428, 821-827.

Yachi, S., \& Loreau, M. (1999). Biodiversity and ecosystem productivity in a fluctuating environment: The insurance hypothesis. Proceedings of the National Academy of Sciences of the United States of America, 96, 1463-1468.

Zedda, L., \& Rambold, G. (2015). The Diversity of Lichenised Fungi: Ecosystem Functions and Ecosystem Services. In D. K. Upreti, P. K. Divakar, V. Shukla, \& R. Bajpai (Eds.), Recent Advances in Lichenology (pp. 121-145). New Delhi: Springer India.

Zellweger, F., De Frenne, P., Lenoir, J., Rocchini, D., \& Coomes, D. (2019). Advances in Microclimate Ecology Arising from Remote Sensing. Trends in Ecology \& Evolution. doi: 10.1016/j.tree.2018.12.012. 


\section{Tables}

Table 1. Distribution of sampling units across spatial scales and land use strata.

\begin{tabular}{lccccccc}
\hline \multirow{2}{*}{ Landuse strata } & \multicolumn{3}{c}{ Epiphytic } & & \multicolumn{3}{c}{ Rock-dwelling } \\
\cline { 2 - 4 } \cline { 6 - 8 } \cline { 6 - 8 } & Plots & Trees & Quadrats & & Plots & Rocks & Quadrats \\
\hline Stone pine stands & 6 & 25 & 500 & & 3 & 10 & 250 \\
Broadleaved forest & 12 & 50 & 1000 & & 12 & 40 & 1000 \\
Cork oak plantations & 7 & 23 & 460 & & 7 & 22 & 550 \\
Croplands & 5 & 14 & 280 & & 5 & 16 & 400 \\
Agro-forestry & 3 & 8 & 160 & & 3 & 12 & 300 \\
Agro-natural land & 5 & 15 & 300 & & 5 & 16 & 400 \\
Pastures & 12 & 36 & 720 & & 12 & 39 & 975 \\
Maquis and shrublands & 11 & 28 & 560 & & 14 & 49 & 1225 \\
Garigue and bare rock & 3 & 7 & 140 & & 5 & 25 & 625 \\
\hline Total & $\mathbf{6 4}$ & $\mathbf{2 0 6}$ & $\mathbf{4 1 2 0}$ & & $\mathbf{6 6}$ & $\mathbf{2 2 9}$ & $\mathbf{5 7 2 5}$
\end{tabular}


Table 2. Functional traits considered in this study and attributed to epiphytic and rock-dwelling lichen species following Nimis \& Martellos (2017).

\begin{tabular}{lll}
\hline \multicolumn{1}{c}{ Functional trait } & Attribute & \multicolumn{1}{c}{ Description } \\
\hline Growth form $(\mathrm{GW})$ & $\mathrm{F}$ & non-lichenized, non-lichenicolous fungus \\
& LF & lichenicolous fungus \\
Cr & crustose \\
Cr.end & crustose endolithic \\
& Cr.pl & crustose placodiomorph \\
& Lepr & leprose \\
Sq & squamulose \\
& Fol.b & foliose broad-lobed \\
& Fol.n & foliose narrow-lobed \\
& Fol.u & foliose umbilicate \\
& Frut & fruticose \\
& Frut.f & fruticose filamentous \\
& N.Ph & non-photosynthetic* \\
& Ch & photosynthetic with Chlorococcoid green algae \\
& Tr & photosynthetic with Trentepohlia pigments \\
& Cy.h & photosynthetic with filamentous cyanobacteria \\
& Cy.c & photosynthetic with coccaceous cyanobacteria \\
& S & mainly sexual by means of ascospores \\
& A.s & mainly asexual, by soredia, or soredia-like structures \\
& A.i & mainly asexual, by isidia, or isidia-like structures \\
A.f & mainly asexual, by thallus fragmentation \\
\hline
\end{tabular}

* attribute not included in Nimis \& Martellos (2017); here used for non-lichenized fungi usually considered by lichenologists, therefore attributed to species with F growth form. 
Table 3. Summary of the Generalized Linear Mixed Modelling (GLM) testing for main and interactive effects of landuse (L, nine levels), plot (random effect nested within L) and substrate type (S, two levels: rock outcrops, tree bark) on total transmitted solar radiation measured at rock outcrop/ tree level.

\begin{tabular}{lcccccc}
\hline & Effect type & df & SS & MS & F & P \\
\hline Total transmitted solar radiation & & & & & & \\
Landuse class (L) & Fixed & 8 & 243.6 & 30.5 & 17.4 & $<0.0001$ \\
Substrate (S) & Fixed & 1 & 789.6 & 789.6 & 1086.6 & $<0.0001$ \\
Plot(Nested within L) & Random & 69 & 116.0 & 1.7 & 2.3 & $<0.0001$ \\
L x S & Fixed & 8 & 242.1 & 30.3 & 41.6 & $<0.0001$ \\
Error & & 348 & 226.0 & 0.7 & & \\
\hline
\end{tabular}


Table 4. Summary of the Generalized Linear Modelling (GLM) testing for main and interactive effects of substrate type ( $\mathrm{S}$, two levels: rock outcrops, tree bark) and transmitted solar radiation (partitioned into the two direct and diffused components, both treated as continuous covariates) on functional over-redundancy (FOR) and vulnerability (FV).

\begin{tabular}{lccccc}
\hline & df & SS & MS & F & P \\
\hline Functional over-redundancy (FOR) & & & & & \\
$\quad$ Substrate (S) & 1 & 887.5 & 887.5 & 6.873 & 0.009 \\
Trasmitted direct solar radiaton (Tdir) & 1 & 506.9 & 506.9 & 3.926 & 0.048 \\
Trasmitted diffused solar radiaton (Tdif) & 1 & 680.2 & 680.2 & 5.268 & 0.022 \\
S x Tdir & 1 & 506.4 & 506.4 & 3.922 & 0.048 \\
S x Tdif & 1 & 178.8 & 178.8 & 1.385 & 0.240 \\
Error & 429 & 55392.6 & 129.1 & & \\
& & & & & \\
Functional vulnerability (FV) & & & & & \\
Substrate (S) & 1 & 11.3 & 11.3 & 0.030 & 0.862 \\
$\quad$ Trasmitted direct solar radiaton (Tdir) & 1 & 2045.1 & 2045.1 & 5.464 & 0.020 \\
Trasmitted diffused solar radiaton (Tdif) & 1 & 2169.0 & 2169.0 & 5.795 & 0.016 \\
S x Tdir & 1 & 2379.1 & 2379.1 & 6.356 & 0.012 \\
S x Tdif & 1 & 1880.3 & 1880.3 & 5.024 & 0.026 \\
$\quad$ Error & 429 & 160568.1 & 374.3 & & \\
\hline
\end{tabular}




\section{Figure captions}

Figure 1. Violin plots showing FOR and FV density distributions across spatial levels for epiphytic and rock-dwelling lichens. Letters above numbers bracketed below violins, white bars, dots and whiskers indicate significantly different groups (Tuckey's unequal N HSD post-hoc test, $P<0.05$ ), sample size, medians, means and $95 \%$ confidence intervals, respectively.

Figure 2. Scatterplots and logarithmic fit of FOR and FV as a function of species richness, across spatial levels for epiphytic (green dots and lines) and rock-dwelling (brown-yellow) lichens. Solid and dotted lines indicate statistically significant $(P<0.05)$ and not significant logarithmic regression models, respectively.

Figure 3. Total transmitted solar radiation measured at tree/rock level across land use strata. Data refer to medians (bars), interquartile ranges (boxes) and non-outlier ranges (whiskers). Letters above whiskers indicate significantly different groups (Duncan post-hoc test for the landuse $\times$ substrate effect, $P<0.05)$.

Figure 4. FOR (top) and FV (bottom) at tree/rock level as a function of direct (left) and diffused (right) transmitted solar radiation. 
Highlights ( 3 to 5 , each max 85 characters, spaces included)

- Functional redundancy at high taxonomic diversity should ensure ecosystem stability

- Functional over-redundancy (FOR) is expected to foster functional vulnerability (FV)

- We explored Mediterranean lichen diversity across spatial and severity gradients

- Lichen FOR and FV decouple at increasing spatial scale, most on harsh rock outcrops

- High taxonomic diversity may not ensure buffering of climate change impacts 

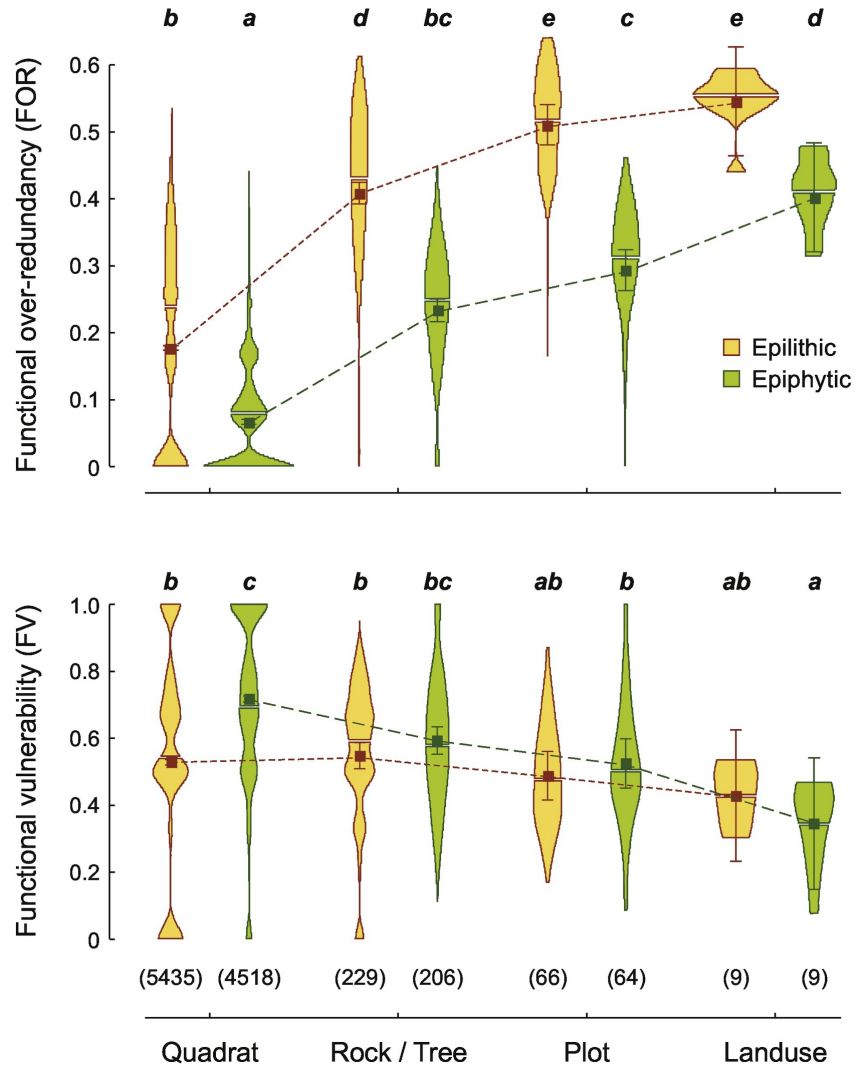

Figure 1 

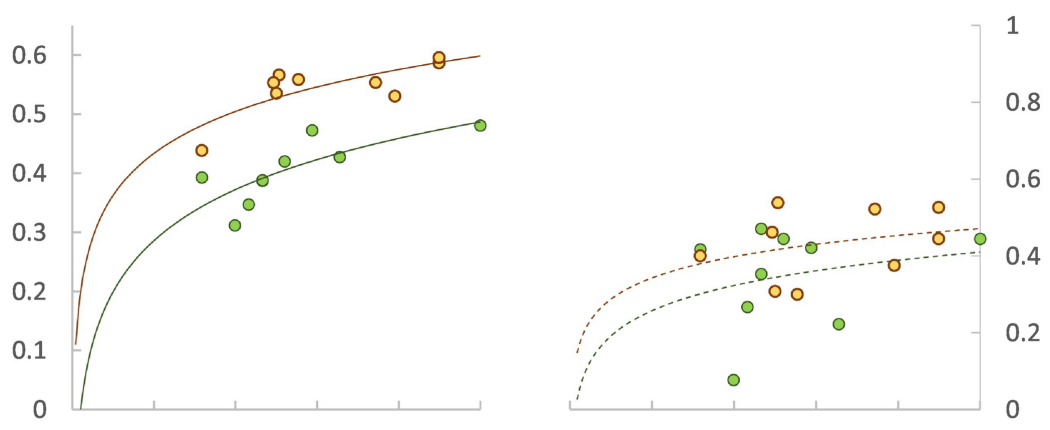

Plot
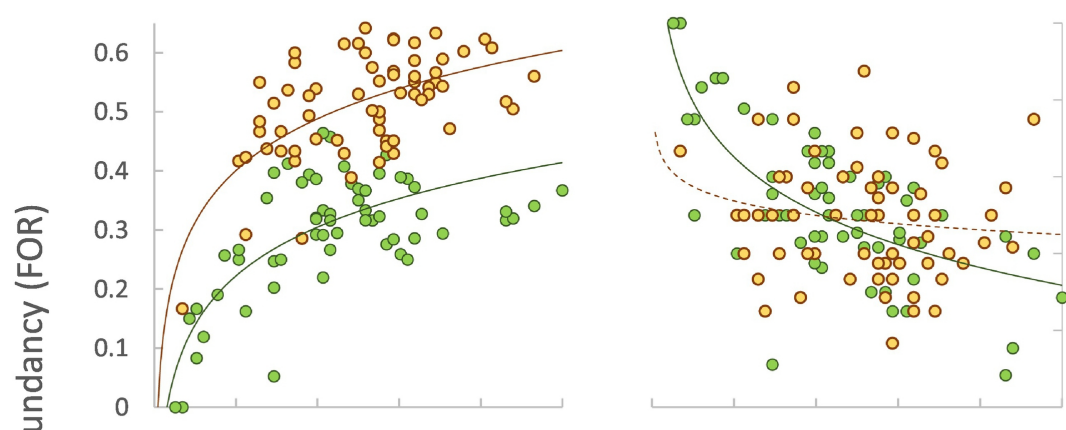

Tree / Rock
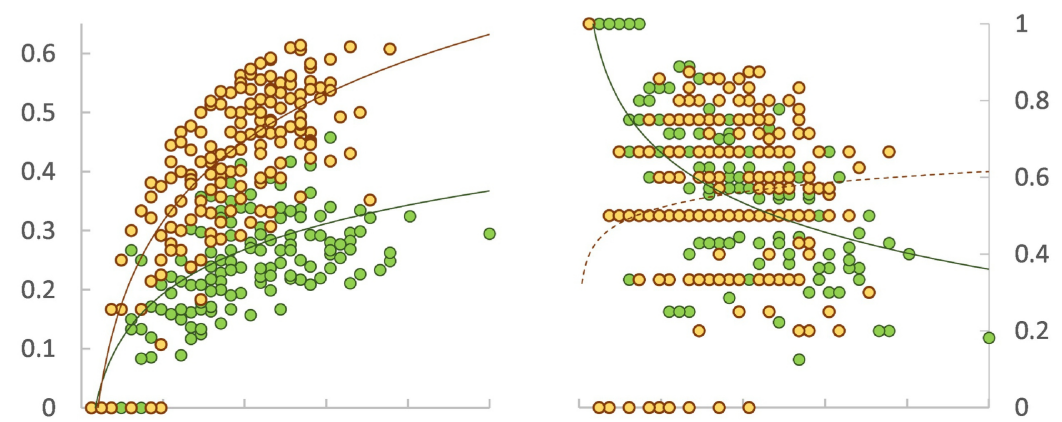

\section{Quadrat}

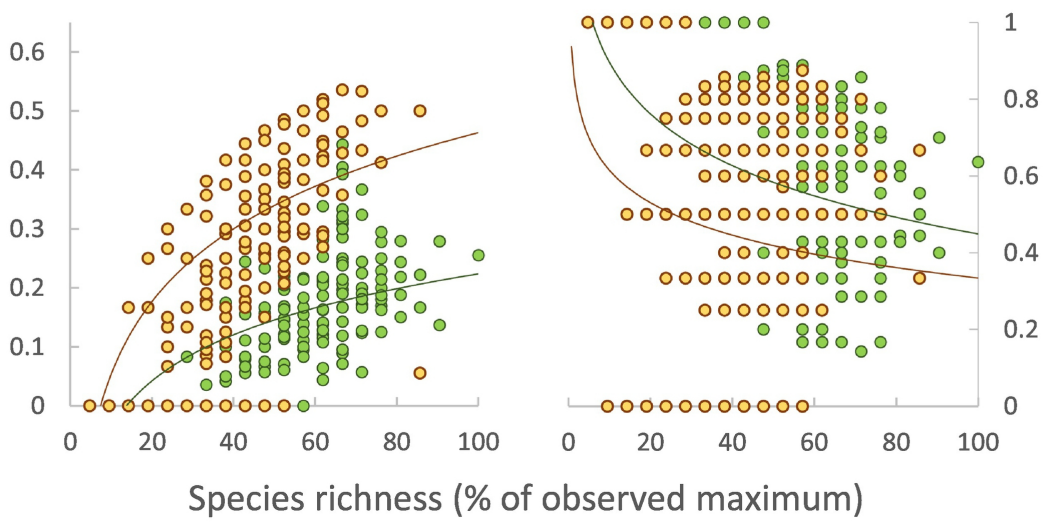




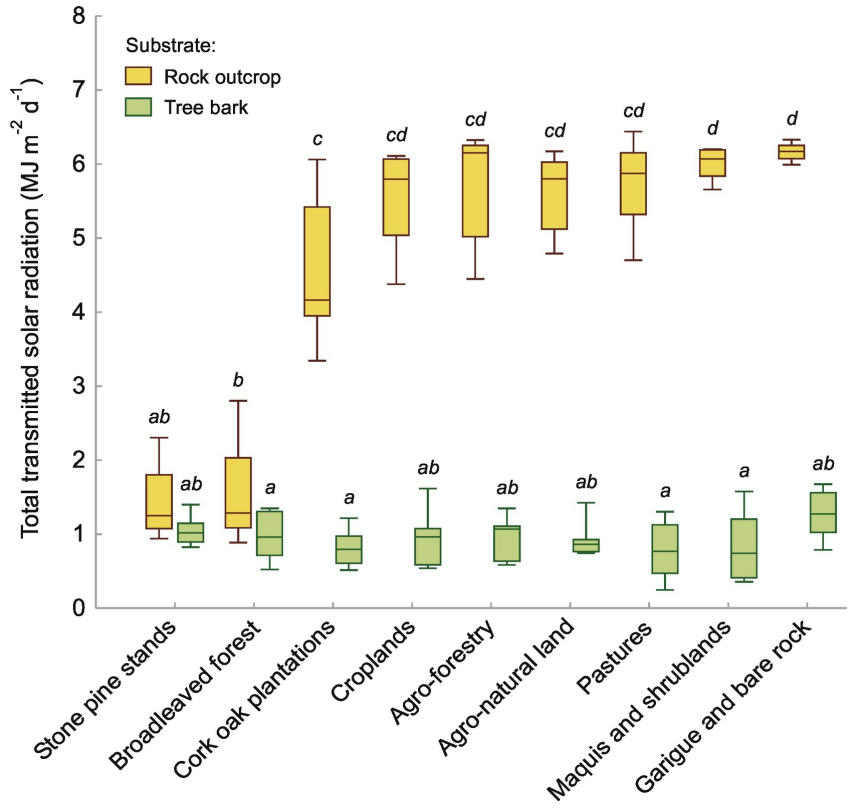

Figure 3 
Direct transmitted
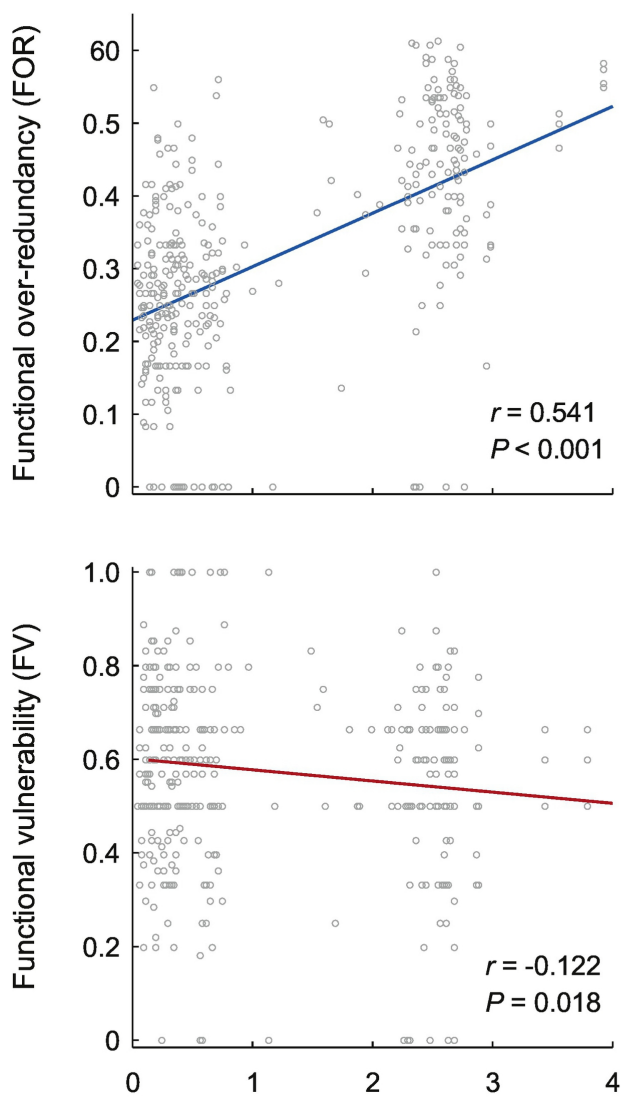

\section{Diffused transmitted}
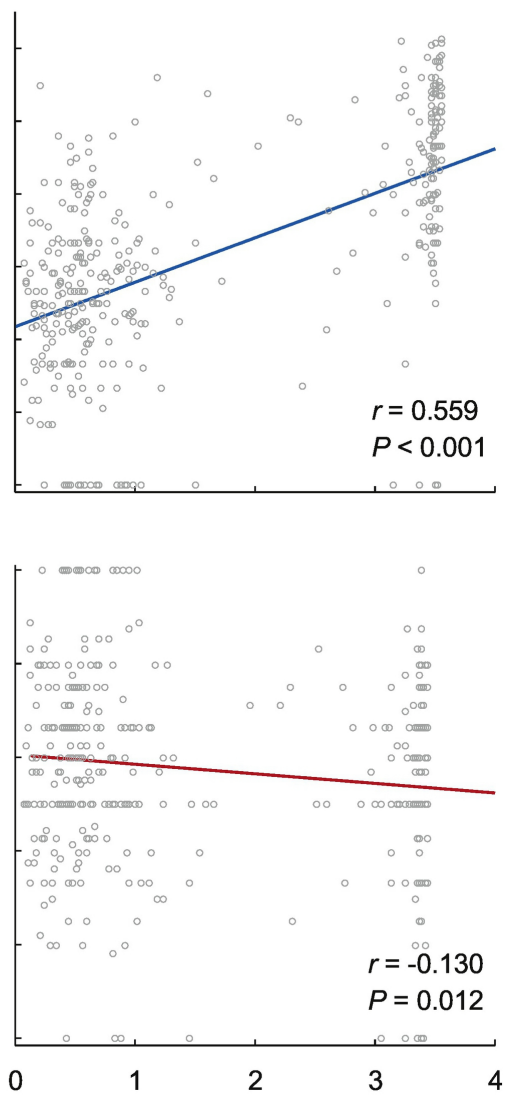

Solar radiation $\left(\mathrm{MJ} \mathrm{m}^{-2} \mathrm{~d}^{-1}\right)$ 